\title{
The Big-Two Model of Personality and Work-Family Conflict
}

\author{
İzlem Gözükara (Corresponding author) \\ Dept. of Business Administration, Istanbul Arel University \\ Türkoba Mahallesi Erguvan Sokak No:26 / K 34537 \\ Tepekent - Büyükçekmece, Istanbul, Turkey \\ Tel: (+90) 2128502735 (ext. 1203) E-mail: izlemg@arel.edu.tr
}

\author{
Ömer Şimşek \\ Dept. of, Psychology, Istanbul Arel University \\ Türkoba Mahallesi Erguvan Sokak No:26 / K 34537 \\ Tepekent - Büyükçekmece, Istanbul, Turkey \\ Tel: (+90) 2128502735 (ext. 1017) E-mail: omersimsek@arel.edu.tr
}

Received: January 16, 2016 Accepted: February 01, 2016 Published: February 28, 2016

doi:10.5296/ijhrs.v6i1.9060 URL: http://dx.doi.org/10.5296/ijhrs.v6i1.9060

\begin{abstract}
Personality traits can be categorized using a hierarchical structure in accordance with their correlations. Such hierarchy is derived by collecting more specific personality traits with similar underlying sources under a more general trait. Personality traits affect how people behave and perceive situations in multiple life domains. Prior research demonstrated the predictive value of the personality variables in multiple role occupation; however, most researchers have used the Big-Five personality traits. Therefore, the present study aims to discuss work-family conflict from the perspective of the Big-Two model of personality. The study sample included 250 participants. The study data was collected using questionnaires and analyzed by testing a structural equation model. The results showed that individuals who score high in stability experience greater work-family conflict, whereas individuals scoring high in plasticity experience less work-family conflict.
\end{abstract}

Keywords: Personality Traits, The Big-Two Model, Stability, Plasticity, Work-Family Conflict 


\section{Introduction}

Prior personality research revealed multiple factors that can explain the most of the covariation among characteristics of personality. There is still no agreement regarding the precise number or actual nature of such factors. However, the extensive consensus is that only a few major factors of personality are present and the personality dimension can be rationally outlined using these factors.

Personality refers to a number of invisible features and processes that are suggestive of stability in behavioral patterns against opinions, people or objects in the environment (Daft, 2008). The most common approach to personality is the Big-Five model with conscientiousness, extraversion, agreeableness, emotional stability and openness to experience (Goldberg, 1992). Each of the Big-Five factors is a highly broad construct, consisting of a wide range of more specific traits. The Big-Five factor model was derived from statistical analyses conducted to determine which traits tend to occur simultaneously when individuals describe themselves or other people.

Investigations of correlations among the Big-Five traits produced the Big-Two Model of personality, referring to two higher-order factors, Alpha and Beta, which is consistently supported by the confirmatory and exploratory factor analyses (Blackburn et al., 2004). The Alpha factor refers to the high loadings on Agreeableness, Emotional Stability (low Neuroticism), and Conscientiousness, whereas the Beta factor refers to the high loadings on Extraversion and Openness to Experience and lower loadings on Emotional Stability and Conscientiousness (Digman, 1997). In this context, alpha implies the consequence of socialization as developing impulse control and decreasing aggression and neurotic defense. Beta, in turn, is about individual development or self-actualization against individual constriction. The important point to consider is that alpha and beta reflect common factors instead of key constituents, meaning that these two factors capture the majority of common variance in the Big Five dimensions, but not the majority of the total variance of all those dimensions (Ashton et al., 2009).

These two metatraits were then named as Stability and Plasticity by DeYoung et al. (2002), as discussed in the present study. The variance shared between Agreeableness, Emotional Stability (low Neuroticism) and Conscientiousness seems to represent one's ability and disposition to preserve stability by abstaining motivational, emotional and social interruptions, while the variance shared between Extraversion and Openness to Experience represents the ability and disposition to discovery through interaction with behavioral and cognitive novelty (DeYoung et al., 2005).

Personality traits, especially the Big-Five, have been demonstrated to have an impact on behavioral patterns and perception of objective settings in different domains of life (Matthews \& Deary, 1998). It is known that the work and family domains may result in a conflict called work-family conflict. Work-family conflict refers to "a form of inter-role conflict in which the role pressures from the work and family domains are mutually incompatible in some respect" (Greenhaus \& Beutell, 1985, p. 77). This construct is based on the role stress and inter-role conflict theories (Kahn et al., 1964). The extant literature 
discusses this conflict considering its direction, from work to family and from family to work. It is called work-family conflict when the interference is from work to family and family-work conflict when it is the opposite (Mesmer-Magnus \& Viswesvaran, 2005). The present paper examines only work-family conflict and suggests, from a theoretical perspective, that individuals with a stable personality stability are likely to experience greater work-family conflict, whereas individuals with a plastic personality are likely to experience less work-family conflict.

\section{Literature Review}

\subsection{The Big-Two Model of Personality}

The five-factor model is the most commonly used model to describe individual differences in personality (Costa \& McCrae, 1985; Goldberg, 1981). This model includes five broad dimensions or subscales to determine differences in personality: Openness to Experience $(\mathrm{O})$, Conscientiousness (C), Agreeableness (A), Extraversion (E), and Neuroticism (N).

According to the five-factor model, the five factors are orthogonal, in other words uncorrelated. Nevertheless, several studies present data that the five subscales have a constant disposition to correlate. In other words, researchers usually find weak to moderate correlations between the subscales of the Big Five Factors (Digman, 1997). Positive and negative affect scales also have a similar correlation tendency (Watson et al., 1988). Such correlations result from the errors in measurement according to the Big-Five supporters (Hyland, 2011). The five subscales of the Big-Five questionnaires do not provide an excellent measurement of underlying components, leading to errors that cause such correlations (Hyland, 2011).

A different approach to this issue is that there is an actual correlation between the Big-Five factors, which is suggestive of a higher-order organization of traits. This leads to a Big-Two, as produced by the factor analysis of the Big-Five. In this regard, it is not surprising that there is also a Big-One, reflecting a higher-order of trait organization. Each order of trait organization offers an applicable means to define consistent behaviors.

Suggested by Digman (1997), the Big-Two model was developed based on the data from multiple studies, and indicates a higher-order organization of personality factors, which are called Alpha (Emotional stability, Agreeableness, Conscientiousness) and Beta (Extraversion and Openness). DeYoung et al. (2002) and DeYoung (2006) conducted a similar research and renamed Alpha as Stability and Beta as Plasticity. These terms were modified based on the network theory. According to the network theory, an effective network requires stability in order to avoid oscillatory changes as well as plasticity to respond to change (Grossberg, 1987). This means that stability and plasticity must be balanced for a well-regulated network.

Concerning the network theory, a low-stability network refers to overreaction to threatening situations, which results in an increased tendency to negative affect. The Big-Five model typically suggests that negative affect is equivalent to neuroticism, whereas it is equated with lack of stability in the Big-Two model. On the other hand, a low-plasticity network refers to lthe ack of ability to adapt to new situations. The Big-Five model equates positive affect with 
extraversion. However, individuals with openness to experience are also likely to have a disposition to positive affect. Therefore, the Big-Two model suggests that there is a relation between positive affect and plasticity, and lack of negative affect and stability. Accordingly, stability and plasticity reflect personality domains with a broader application theoretically since these domains are consistent with the two-factor theory of affect.

As argued by DeYoung (2006), the Big Two captures these features -stability and plasticity of a network, and offers an approach to understand various forms of dysregulation in the network. This approach suggests characterizing a dysregulated network by low stability or low plasticity, or both.

The Big Two can be interpreted as metatraits of personality, which describe more basic dimensions compared to the Big Five (Becker, 1999). DeYoung et al. (2002), the developers of the Big-Two Model, stated that these two factors are suggestive of the very basic personality tendencies rather than the pure consequences of socialization or individual development. The authors also emphasized that these two factors and conformity are linked because they established a positive correlation between conformity measures and Stability and a negative correlation with Plasticity. In brief, Stability and Plasticity depict the manifestation of the two most extensive needs of a person in personality, the need to maintain a stable psychosocial organization in order to accomplish individual goals and the need to integrate new information into such organization during the internal and external changes individually.

\subsection{Work-Family Conflict}

There has been a considerable progress in the literature on work and family; however, some points still remain unknown. Among others, the individual dispositions to achieve a balanced work-family life have gathered highly little attention (Sumer \& Knight, 2001). The research on work and family has been generally limited to the insufficient angle of inter-role conflict caused by the work and family roles (e.g., Greenhaus \& Beutell, 1985). Based on this angle, work-family conflict is the difficulty to engage in one of these roles due to the engagement in the other role (Greenhaus \& Beutell, 1985).

The traditional approach to engagement in several roles suggests that one has limited time and energy and experiences conflict when there are too many demands (Sieber, 1974). According to Greenhaus and Beutell (1985), the conflict results from time pressure from one role that prevents the fulfillment of other role's expectations, the stress in one role causing weariness and strain with negative impact on performance in other role, or the incompatibility between the actions required by two roles. Additionally, the authors argued that conflict is a bidirectional construct and work-family conflict is the negative impact of individuals' role at work on their role in family. Accordingly, there is also a family-work conflict (FWC), which is defined as the negative impact of individuals' role in family on their role at work.

The work-family conflict, as reported by Greenhaus and Beutell (1985), is a multidimensional concept arising from three types of conflicts: time-based, strain-based and behavior-based. Time-based conflict occurs when the time requirements of a role make it 
physically impossible to meet the expectations of another role or when the time requirements lead to a preoccupation with one role even it is possible to physically meet the expectations of another role. Strain-based conflict occurs when the strain experienced in one role impairs the performance in another role along with strain symptoms such as anxiety. Behavior-based conflict occurs when there is an incompatibility of behaviors required for the two roles.

From a different angle, some scholars and especially sociological researchers (Marks, 1977; Sieber, 1974) had a convincing claim that engagement in several roles has its own merits such as a sense of purpose in life, increased self-respect (Thoits, 1987), social support, security purposes, and intermediary effects versus failure in roles (Barnett \& Hyde, 2001). Research provides evidence that participation in work and family domains have intellectual, physical and relational benefits (Barnett \& Hyde, 2001), and a combined family and work life offers merits that worth the expense (Barnett, 1998).

It is believed that the interaction of personality traits with work and family domains may provide valuable results to have a better understanding of the peculiar nature of enhancing and/or impeding patterns of conflict between work and family domains (Edwards \& Rothbard, 2000). In a supporting sense, Eby et al. (2005) asserted that the individual dispositions have been relatively examined in relation to the work-family conflict. Likewise, Bruck and Allen (2003) proposed that work-family conflict studies should include not only situational but also dispositional variables.

From the framework of the Big-Five model, a consistent correlation has been demonstrated between neuroticism and work-family conflict, whereas recent studies found agreeableness and conscientiousness significantly negatively correlated with work-family conflict and family-work conflict (Bruck \& Allen, 2003; Wayne et al., 2004). In a similar vein, a study by Kinnunen et al. (2003) reported a moderate effect of emotional stability (neuroticism) on the association between work-family conflict and work exhaustion.

According to Spector et al. (2000), negative affect has an influence on one's perception of his/her work and other life domains, and has a relation with stressor and strain reports. Work-family conflict has been demonstrated to be greater in individuals who have greater negative affect (Bruck \& Allen, 2003; Carlson, 1999; Stoeva et al., 2002). Likewise, neuroticism has been consistently reported to have a correlation with both conflicts, WFC and FWC (Grzywacz \& Marks, 2000; Wayne et al., 2004). There are multiple studies regarding the effect of Big-Five factors on work-family conflict. For instance, Bruck and Allen (2003), and Wayne et al. (2004) established that agreeableness and conscientiousness are correlated with work-family conflict. Less agreeable individuals reported greater work-family conflict, whereas more conscientious individuals stated less conflict. There is also a negative correlation between positive affect and both types of conflict (Karatepe \& Uludag, 2008).

According to Kopelman et al.'s (1983) model of work-family conflict, which is widely accepted by several authors, the key contributors to work-family conflict are the structural characteristics of work and family domains. The present paper suggests that such characteristics are likely to be the key contributors, but there may be other significant contributors, such as personality, and aims to examine this construct based on the Big-Two 
model.

Hypothesis 1 . There is a negative relationship between stability and work-family conflict.

Hypothesis 2. There is a positive relationship between plasticity and work-family conflict.

\section{Method}

\subsection{Sample and Data Collection}

A sample of 250 participants $($ Mean $=33.38$, Male $=154$, Female $=96$ ) working at a k-12 school or a higher education institution was selected by convenience sampling method. The collection of all questionnaires was completed in ten weeks and the collected data were analyzed through SPSS 21.0 and LISREL 8.51.

\subsection{Instruments}

Personality traits were measures using the 44-item Big Five Inventory (BFI) developed by John et al. (1991). The inventory consisted of 5 subscales; openness (e.g. "I see myself as someone who is original, comes up with new ideas"), conscientiousness (e.g. "I see myself as someone who perseveres until the task is finished"), extraversion (e.g. "I see myself as someone who is talkative)", agreeableness (.g. "I see myself as someone who is helpful and unselfish with others"), and neuroticism (.g. "I see myself as someone who is depressed, blue"). Participants were asked to indicate the degree to which each statement described their personality using 5 -point ratings $(1=$ strongly disagree, $5=$ strongly agree). The Cronbach's alpha was 0.81 for Openness, 0.82 for Conscientiousness, 0.88 for Extraversion, 0.79 for Agreeableness, and 0.84 for the Neuroticism.

Work-family conflict was measured using the multi-dimensional scale developed by Carlson et al. (2000). The scale consists of 9 items for work-to-family conflict. Three items each measure different dimensions of work-family conflict: time-based WFC (e.g. "The time I must devote to my job keeps me from participating equally in household responsibilities and activities"), strain-based WFC (e.g. "Due to stress at home, I am often preoccupied with family matters at work") and behavior-based WFC (e.g. ".Behavior that is effective and necessary for me at home would be counterproductive at work"). Each item is measured on 5 -point ratings $(1=$ strongly disagree, $5=$ strongly agree $)$. The Cronbach's alpha of the scale was 0.89 .

\section{Results}

The present study uses two-step approach to test the regression model using latent variables. Before testing the structural model in which stability and plasticity regressed on the three factors of work-family conflict, a measurement model was tested in order to see the reliability of the measures used in the study.

\subsection{Results of the Measurement Model}

A test of the measurement model has been accomplished by defining observed variables for each latent variable. As indicated before, plasticity and stability metatraits have been defined 


\section{Macrothink}

International Journal of Human Resource Studies

ISSN 2162-3058 2016, Vol. 6, No. 1

by the Big Five personality traits of neuroticism, agreeableness, conscientiousness, extraversion, and openness to experience, the former three are of stability and the latter two refer to stability. Consequently, composite scores of these traits were used as observed variables of plasticity and stability metatraits. The respective items of the factors of WFC Scale, on the other hand, defined three dimensions of work-family conflict construct. Means and standard deviations of, and intercorrelations among these observed variables are presented in Table 1.

Table 1. Means, Standard Deviations, and Intercorrelations of Observed Variables

\begin{tabular}{|c|c|c|c|c|c|c|c|c|c|c|c|c|c|c|c|}
\hline & Mean & SD & AGR & $\mathrm{CON}$ & NEU & EXT & OPE & Item1 & Item2 & Item3 & Item 4 & Item5 & Item6 & Item 7 & Item8 \\
\hline AGR & 37.03 & 4.79 & - & & & & & & & & & & & & \\
\hline $\mathrm{CON}$ & 31.09 & 3.66 & .46 & - & & & & & & & & & & & \\
\hline NEU & 22.72 & 5.22 & -.22 & -.34 & - & & & & & & & & & & \\
\hline EXT & 30.29 & 5.75 & .37 & .30 & -.20 & - & & & & & & & & & \\
\hline OPE & 39.14 & 5.80 & .29 & .21 & -.09 & .41 & - & & & & & & & & \\
\hline Item1 & 2.99 & 1.29 & -.12 & -.05 & .04 & -.02 & -.05 & - & & & & & & & \\
\hline Item2 & 2.84 & 1.28 & -.18 & -.10 & .06 & -.08 & -.09 & .84 & - & & & & & & \\
\hline Item3 & 2.72 & 1.25 & -.15 & -.11 & .08 & -.05 & -.12 & .76 & .85 & - & & & & & \\
\hline Item4 & 2.99 & 1.28 & -.11 & -.13 & .06 & -.13 & -.10 & .67 & .71 & .64 & - & & & & \\
\hline Item5 & 2.70 & 1.30 & -.28 & -.28 & .14 & -.10 & -.07 & .65 & .65 & .65 & .76 & - & & & \\
\hline Item6 & 2.64 & 1.29 & -.33 & -.38 & .20 & -.13 & -.14 & .47 & .51 & .50 & .51 & .67 & - & & \\
\hline Item7 & 2.69 & 1.28 & -.25 & -.19 & .21 & -.18 & -.22 & .39 & .43 & .42 & .38 & .43 & .47 & - & \\
\hline Item8 & 2.42 & 1.21 & -.27 & -.29 & .22 & -.15 & -.16 & .39 & .45 & .48 & .36 & .49 & .56 & .66 & - \\
\hline Item 9 & 2.57 & 1.24 & -.25 & -.27 & .24 & -.11 & -.10 & .34 & .38 & .39 & .34 & .44 & .44 & .63 & .69 \\
\hline
\end{tabular}

Notes: $N=250 ;$ AGR $=$ Agreeableness, $\mathrm{CON}=$ Conscientiousness, $\mathrm{NEU}=$ Neuroticism, EXT $=$ Extraversion, OPE $=$ Openness to experience, Item1-Item9 = Items of the Work Family Conflict Questionnaire; values above .13 are statistically significant at $\mathrm{p}=.05$.

A test of the measurement model resulted in acceptable goodness of fit statistics: $\chi^{2}(67, N=$ $250)=161.43, p<0.05$; Goodness-of-fit Index $(\mathrm{GFI})=.92$, Normed Fit Index $(\mathrm{NFI})=0.92$, Comparative Fit Index $(\mathrm{CFI})=0.95$, Incremental Fit Index (IFI) $=0.95$, Root Mean Square Error of Approximation (RMSEA) $=0.075$ (90 percent confidence interval for RMSEA $=$ 0.060-0.090). As seen in Table 2, all factor loadings of the observed variables were large and statistically significant. 


\section{Macrothink}

Table 2. Factor Loadings, standard errors, and t-values for the Measurement Model

\begin{tabular}{|c|c|c|c|c|}
\hline $\begin{array}{l}\text { Measure and } \\
\text { Variable }\end{array}$ & $\begin{array}{l}\text { Unstandardized } \\
\text { Factor Loading }\end{array}$ & $\mathrm{SE}$ & $\mathrm{t}$-Value & $\begin{array}{c}\text { Standardized Factor } \\
\text { Loading }\end{array}$ \\
\hline \multicolumn{5}{|l|}{ Stability } \\
\hline AGR & 2.80 & 0.30 & 9.29 & .62 \\
\hline $\mathrm{CON}$ & 2.42 & 0.24 & 10.09 & .67 \\
\hline NEU & -2.64 & 0.37 & -7.24 & -.50 \\
\hline \multicolumn{5}{|l|}{ Plasticity } \\
\hline EXT & 4.30 & 0.44 & 9.84 & .81 \\
\hline OPE & 3.30 & 0.42 & 8.81 & .58 \\
\hline \multicolumn{5}{|l|}{ Time-Based } \\
\hline \multicolumn{5}{|l|}{ WFC } \\
\hline Item 1 & 1.16 & 0.07 & 17.62 & .89 \\
\hline Item 2 & 1.21 & 0.06 & 19.60 & .94 \\
\hline Item 3 & 1.10 & 0.06 & 17.25 & .87 \\
\hline \multicolumn{5}{|l|}{ Strain-Based } \\
\hline \multicolumn{5}{|l|}{ WFC } \\
\hline Item 4 & 1.08 & 0.07 & 15.38 & .82 \\
\hline Item 5 & 1.18 & 0.07 & 17.70 & .90 \\
\hline Item 6 & 0.98 & 0.07 & 13.31 & .74 \\
\hline \multicolumn{5}{|c|}{ Behavior-Based } \\
\hline \multicolumn{5}{|l|}{ WFC } \\
\hline Item 7 & 0.94 & 0.07 & 13.10 & .74 \\
\hline Item 8 & 1.14 & 0.06 & 18.36 & .94 \\
\hline Item 9 & 0.96 & 0.07 & 14.62 & .80 \\
\hline
\end{tabular}

The correlations among the latent constructs are presented in Table 3. According to the latent correlations calculated using LISREL 8.5, most of the constructs were correlated each other strongly, the strongest correlation was between two dimensions of WFC, i.e. Time-based and Strain-based WFC. The correlations of Plasticity with the dimensions of WFC were all weak. The correlation between Stability and Time-based WFC was also weak. Finally, all correlations of big-two metatraits negatively correlated with WFC dimensions. 
Table 3. Intercorrelations of Latent Constructs

\begin{tabular}{|c|c|c|c|c|c|}
\hline Latent Variable & Stability & Plasticity & $\begin{array}{r}\text { Time-Based } \\
\text { WFC }\end{array}$ & $\begin{array}{r}\text { Strain-Based } \\
\text { WFC }\end{array}$ & $\begin{array}{r}\text { Behavior-Based } \\
\text { WFC }\end{array}$ \\
\hline Stability & - & & & & \\
\hline Plasticity & .72 & - & & & \\
\hline $\begin{array}{l}\text { Time-Based } \\
\text { WFC }\end{array}$ & -.20 & -.10 & - & & \\
\hline $\begin{array}{l}\text { Strain-Based } \\
\text { WFC }\end{array}$ & -.47 & -.22 & .83 & - & \\
\hline $\begin{array}{l}\text { Behavior-Based } \\
\text { WFC }\end{array}$ & -.52 & -.24 & .52 & .61 & - \\
\hline
\end{tabular}

Notes: $N=250$; All values above 0.10 are statistically significant at $\mathrm{p}=.05$.

\subsection{Results of the Structural Model}

A test of the structural model with Maximum Likelihood estimation method also yielded again acceptable goodness of fit statistics: $\chi^{2}(70, N=250)=194.08, p<0.05$; Goodness-of-fit Index $(\mathrm{GFI})=0.90$, Normed Fit Index $(\mathrm{NFI})=0.91$, Comparative Fit Index $(\mathrm{CFI})=0.94$, Incremental Fit Index $(\mathrm{IFI})=0.94$, Root Mean Square Error of Approximation $($ RMSEA $)=0.084$ (90 percent confidence interval for RMSEA $=0.070-0.099)$.

However, modification indices produced by the LISREL program indicated that the error variances of the dependent variables in the model should be correlated. Adding the covariances among the error variances of three dependent latent variables yielded acceptable goodness of fit statistics: $\chi^{2}(67, N=250)=161.43, p<.05$; Goodness-of-fit Index (GFI) $=.92$, Normed Fit Index $(\mathrm{NFI})=0.92$, Comparative Fit Index $(\mathrm{CFI})=0.95$, Incremental Fit Index $($ IFI $)=.95$, Root Mean Square Error of Approximation $($ RMSEA) $=0.075$ (90 percent confidence interval for RMSEA $=0.060-0.090)$.

According to the results of the regression model, stability negatively correlated with the three dimensions of WFC: while its correlation with time-based WFC was weak, correlations with strain-based and behavior-based WFC were strong. Plasticity, on the other hand, correlated weakly and positively with the three dimensions of WFC (Figure 1). 


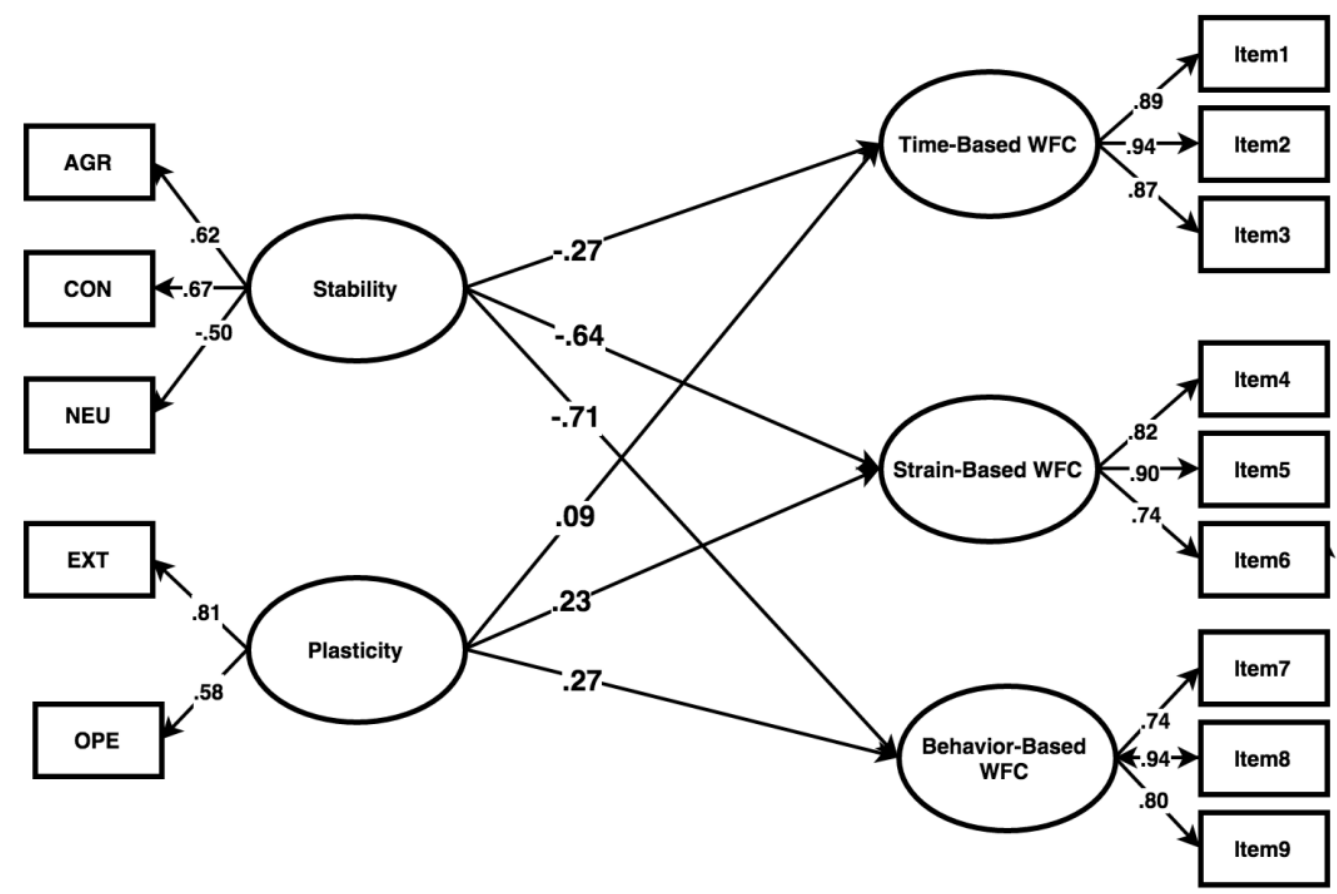

Figure 1. Standardized parameter estimates for the proposed model.

Notes: $N=250 ;$ All parameter estimates above .10 are statistically significant at $\mathrm{p}=.05$.

\section{Conclusion and Practical Implications}

The present paper examined the conflict between work and family roles based on the Big-Two model of personality. The Big-Two model assumes two broad personality organizations, Stability and Plasticity, which are the higher-order factors of the Big Five. According to DeYoung et al. (2002), these two factors should be considered complementary. More specifically, plasticity is needed to maintain stability in new situations, whereas relational and emotional stability enable security in case of novel situations (Just, 2011).

The results from the present research demonstrated that stability has a negative correlation with work-family conflict, and plasticity is positively correlated with work-family conflict. In this sense, the present paper provides a significant contribution to the available literature by discussing work-family conflict from the perspective of the Big-Two model and demonstrating the relationships between personality traits and work-family conflict. Prior research on work-family conflict has usually adopted the traditional view considering only the inter-role conflicts and there is a very limited number of studies examining the impact of individual dispositions based on the Big-Two model. In line with Edwards and Rothbard (2000), the present study suggests that individual dispositions can offer a valuable insight to the specific nature of work-family conflict by revealing personality traits with inhibiting or promoting effects on such conflict.

The first important finding of the study demonstrated that there is a negative correlation between stability and all three types of work-family conflict. The strongest negative correlation was found between stability and behavior-based conflicts (-0.71 for 
behavior-based, -0.64 for strain-based and -0.27 for time-based conflict). The stability metatrait involves agreeableness, conscientiousness and low neuroticism. Agreeableness is a personality trait reflecting individual differences in social adaptation and cooperativeness. Individuals scoring high in this dimension are characterized as kind, helpful, sympathetic, cooperative and friendly with a tendency to be more sensitive to others' perspectives, whereas those scoring low in agreeableness are likely to be perceived as competitive and egocentric with less concern for others' needs or intentions (Costa \& McCrae, 1991; Thompson, 2008).

This dimension also includes compliance as a facet of agreeableness, which refers to one's response to conflicts (Costa \& McCrae, 1991). People with low compliance scores are likely to be aggressive, unfriendly and malicious, whereas those scoring high tend to be cooperative and compliant in order to resolve conflicts. This may be the mechanism underlying the finding of the study indicating that individuals who score high in agreeableness have less work-family conflict for all three types. Future studies may extend the present research by including the lower-traits of agreeableness to examine which facets are responsible for the said finding and how agreeable people handle the conflicts in question.

The second personality trait grouped under stability is conscientiousness, which reflects individual differences in organization and planning (Costa \& McCrae, 1991). Those with high scores are vigilant, careful, reliable, organized and efficient, whereas low-score individuals are likely to be unreliable, careless and less success-driven. It has been reported that role ambiguity has less influence on individuals scoring high in conscientiousness (Barrick \& Mount, 1991; Salgado, 1997). Since role ambiguity is a role stressor related to work-family conflict (Aryee, 1992), it is likely to expect from more conscientious individuals to experience less work-family conflict, which was confirmed in the present study. This finding suggests that those who effectively manage time, tasks and responsibilities with skills to organize and plan would easily resolve conflicts they experience between work and family, and experience especially low levels of strain- and time-based conflicts. Future studies may investigate why strain- and time-based conflicts are experienced at lower levels compared to behavioral-based conflict by such individuals.

The last personality trait included in stability is emotional stability, i.e. low neuroticism, which reflects impulse control. Emotionally stable people are likely to show less reaction to stress and exhibit calmness. Those who are emotionally unstable, in turn, have a greater tendency to feel anxiety, fear, anger and jealousy (Matthew \& Deary, 1998). People scoring high in emotional stability have better coping mechanisms and impulse control, which was shown to have a positive relation with self-reported stress (Hills \& Norvell, 1991). Accordingly, the finding of the present study on lower conflicts based on time, strain and behavior in emotionally stable individuals is consistent with the manifestation of emotional stability in individual behaviors. Future studies may examine how such individuals build these coping mechanisms for a better understanding.

The second important finding of the study was the positive correlation between plasticity and all three types of work-family conflict. Even though this is a relatively mild relationship, it is still significant to demonstrate the influence of plasticity on conflicts between work and life 
domains. Among the lower-traits of plasticity, the strongest relationship was found between behavioral-based conflict and plasticity ( 0.27 for behavior-based, 0.23 for strain-based and 0.09 for time-based conflict). This metatrait includes openness to experience (intellect) and extraversion dimensions. Costa and McCrae (1991) describes openness to experience with six facets: active imagination, aesthetic sensitivity, intellectual curiosity, preference for variety, and independence of judgment. People scoring high in this dimension are likely to be more liberal and innovative, whereas those with low scores tend to be more conservative and prefer familiar routines. Individuals who are open to experience enjoy new ideas and are curious about everything. These characteristics may be the reason why people who are more open to experiences report greater work-family conflict, especially the behavior-based conflict, as demonstrated in this study. This finding is important since there is no other study reporting a connection between this trait and work-family conflict, either positive or negative. Future studies may expand this research by investigating only openness to experience and evaluating its relationship with behavioral-based conflict, which was found to have the strongest correlation among all three types in the present study.

The second trait included in plasticity is extraversion, which reflects interpersonal interactions. Extraverts are characterized by enjoying a wide variety of activities (Laney \& Olsen, 2002). Extraverts scoring high in this dimension are dynamic, optimistic and enthusiastic with great skills in socialization, whereas introverts scoring low are likely to be quiet, deliberate and less involved in social life (Costa \& McCrae, 1991). Since extraverts have a desire for all external means, it seems reasonable that such individuals experience greater conflicts between their work and life. Future studies may specifically explore how to develop a balanced life for extravert individuals.

In conclusion, the findings of this study suggest that time-, strain- and behavior-based conflicts can be avoided when one has the ability to cooperate and empathize, skills to organize and plan, and mechanisms to cope with stress. In this regard, this study offers a significant contribution to the literature on human resources, organizational management and organizational health. Today, human resources management use several personality inventories at the employment stage to determine whether an individual fits both the position and the organization. Since the results from this research suggest that individuals who are more stable in personality would experience less conflict between their work and family roles, organizations may consider implementing support programs in order to help their employees to balance their life domains. Such support may include supervisor support, co-worker support or spouse support due to the positive influence of significant others on individuals' attitudes and behaviors. Organizations may also provide an environment fostering cooperation for this purpose.

Given that individuals who are more plastic in personality would have higher levels of work-family conflict, organizations may consider providing individuals who enjoy social engagement and self-expression with a more creative and flexible working environment, socialization activities and challenging assignments in order to prevent or reduce all three types of work-family conflict experienced by such employees. Organizations should formulate training programs that can help employees to develop planning and time 
management skills to minimize work-family conflict. Furthermore, organizations can also formulate coaching or training programs based on general personality traits in order to help individuals to understand the basics of their personality and modify their behavior accordingly. For instance, training programs can focus on helping individuals with a neurotic personality to realize that they have a disposition to perceive many situations negatively and that they can minimize perception of threats all the time. Thereby, there would be less conflict between work and family lives and employees may have greater satisfaction while organizations lower the costs stemming from such a conflict.

\section{References}

Aryee, S. (1992). Antecedents and outcomes of work-family conflict among married professional women: Evidence from Singapore. Human Relations, 45, 813-837. http://dx.doi.org/10.1177/001872679204500804

Barnett, R. C. (1998). Toward a review and reconceptualization of the work/family literature. Genetic, Social, and General Psychology Monographs, 124(2), 125-182.

Barnett, R. C., \& Hyde, J. S. (2001). Women, men, work, and family: An Expansionist $\begin{array}{llll}\text { Theory. American } \quad \text { Psychologist, } & \text { 56(10), }\end{array}$ http://dx.doi.org/10.1037/0003-066X.56.10.781

Barrick, M. R., \& Mount, M. K. (1991). The Big Five personality dimensions and job performance: A meta-analysis. Personnel Psychology, 44, 1-26. http://dx.doi.org/ 10.1111/j.1744-6570.1991.tb00688.x

Becker, P. (1999). Beyond the Big Five. Personality and Individual Differences, 26, 511-530. http://dx.doi.org/10.1016/S0191-8869(98)00168-8

Blackburn, R., Renwick, S. J. D., Donnelly, J. P., \& Logan, C. (2004). Big Five or Big Two? Superordinate factors in the NEO five factor inventory and the antisocial personality questionnaire. Personality and Individual Differences, 37, 957-70. http://dx.doi.org/ 10.1016/j.paid.2003.10.017

Bruck, C. S., \& Allen, T. D. (2003). The relationship between big five personality traits, negative affectivity, type A behavior, and work-family conflict. Journal of Vocational Behavior, 63, 457-472. http://dx.doi.org/10.1016/S0001-8791(02)00040-41

Carlson, D. S. (1999). Personality and role variables as predictors of three forms of work-family conflict. Journal of Vocational Behavior, 55, 236-253. http://dx.doi.org/10.1006/jvbe.1999.1680

Carlson, D. S., Kacmar, M. K., \& Williams, L. J. (2000). Construction and validation of a multidimensional measure of work-family conflict. Journal of Vocational Behavior, 56(2), 249-276. http://dx.doi.org/10.1006/jvbe.1999.1713

Costa, P. T., Jr., \& McCrae, R. R. (1985). The NEO personality inventory manual. Odessa, FL: Psychological Assessment Resources. 


\section{Macrothink}

International Journal of Human Resource Studies ISSN 2162-3058 2016, Vol. 6, No. 1

Costa, P. T., \& McCrae, R. R. (1991). Revised NEO personality inventory (NEO PI-R) and NEO fivefactor inventory (NEO-FFI): Professional Manual. Odessa, FL: Psychological Assessment Resources.

Daft, R. L. (2008). Leadership (5th ed.). Cincinnati, OH: Thompson/South-Western.

DeYoung, C. G., Peterson, J. B., \& Higgins, D. M. (2002). Higher-order factors of the Big Five predict conformity: Are there neuroses of health? Personality and Individual Differences, 33, 533-552. http://dx.doi.org/ 10.1016/S0191-8869(01)00171-4

DeYoung, C. G. (2006). Higher-order factors of the Big Five in a multiinformant sample. Journal of Personality and Social Psychology, 91, $1138-1151$. http://dx.doi.org/10.1037/0022-3514.91.6.1138

Digman, J. M. (1997). Higher-order factors of the big five. Journal of Personality and Social Psychology, 73, 1246-1256. http://dx.doi.org/10.1037/0022-3514.73.6.1246

Eby, L. T., Casper, W. J., Lockwood, A., Bordeaux, C., \& Brinley, A. (2005). Work and family research in IO/OB: Content analysis and review of the literature (1980- 2002). Journal of Vocational Behavior, 66, 124-197. http://dx.doi.org/10.1016/j.jvb.2003.11.003

Edwards, J. R., \& Rothbard, N. P. (2000). Mechanisms linking work and family: Clarifying the relationship between work and family constructs. Academy of Management Review, 25, 178-199. http://dx.doi.org/10.5465/AMR.2000.27916093

Goldberg, L. R. (1981). Language and individual differences: The search for universals in personality lexicons. In L. Wheeler (Ed.), Review of personality and social psychology (Vol. 2, pp. 141-165). Beverly Hills, CA: Sage. http://dx.doi.org/10.1037/0022-3514.59.6.1216

Goldberg, L. R. (1992). The development of markers for the Big Five factor structure. Psychological Assessment, 4, 26-42. http://dx.doi.org/10.1037/1040-3590.4.1.26

Greenhaus, J., \& Beutell, N. (1985). Sources and conflict between work and family roles. Academy of Management Review, 10, 76-88. http://dx.doi.org/10.5465/AMR.1985.4277352

Grossberg,S. (1987). Competitive learning: from interactive activation to adaptive resonance. Cognitive Science, 11, 23-63. http://dx.doi.org/10.1016/S0364-0213(87)80025-3

Grzywacz, J. G., \& Marks, N. F. (2000). Reconceptualizing the work-family interface: An ecological perspective on the correlates of positive and negative spillover between work and family. Journal of Occupational Health Psychology, 5(1), 111-126. http://dx.doi.org/10.1037/1076-8998.5.1.111

Hills, H., \& Norvell, N. (1991). An examination of hardiness and neuroticism as potential moderators of stress outcomes. Behavioral Medicine, 17, 31-38. http://dx.doi.org/10.1080/08964289.1991.9937550

Hyland, M. E. (2011). The origins of health and disease. Cambridge: Cambridge University Press. http://dx.doi.org/10.1017/CBO9780511976216 
Kahn, R. L., Wolfe, D. M., Quinn, R., Snoek, J. D., \& Rosenthal, R. A. (1964). Organizational stress. New York: Wiley.

Karatepe, O. M., \& Uludag, O. (2008). Affectivity, conflicts in the work-family interface, and hotel employee outcomes. International Journal of Hospitality Management, 27, 30-41. http://dx.doi.org/10.1016/j.ijhm.2007.07.001

Kopelman, R., Greenhaus, J., \& Connolly, T. (1983). A model of work, family, and interrole conflict: A construct validation study. Organizational Behavior and Human Performance, 32, 198-215. http://dx.doi.org/10.1016/0030-5073(83)90147-2

Laney, M.O. (2002). The introvert advantage. Canada: Thomas Allen \& Son Limited. pp. 28-35.

Marks, S. R. (1977). Multiple roles and role strain: Some notes on human energy, time, and commitment. American Sociological Review, 42, 921-936. http://dx.doi.org/10.2307/20945772

Matthews, G., \& Deary, I. J. (1998). Personality traits. Cambridge, UK: Cambridge University Press. http://dx.doi.org/10.1017/CBO9780511812743

Mesmer-Magnus, J. R., \& Viswesvaran, C. (2006). How family-friendly work environments affect work/family conflict: A meta-analytic examination. Journal of Labor Research, 27, 555-574. http://dx.doi.org/10.1007/s12122-006-1020-1

Michael C. Ashton, M.C., Lee, K., Goldberg, L.R. \& de Vries, R.E. (2009). Higher Order Factors of Personality: Do They Exist? Personality and Social Psychology Review, 13, 79-91. http://dx.doi.org/10.1177/1088868309338467

Salgado, J. F. (1997). The five factor model of personality and job performance in the European community. Journal of Applied Psychology, 82, 30-43. http://dx.doi.org/10.1037/0021-9010.82.1.30

Sieber, S. D. (1974). Toward a theory of role accumulation. American Sociological Review, 39, 567-578. http://dx.doi.org/10.2307/2094422

Spector, P. E., Zapf, D., Chen, P. Y., \& Frese, M. (2000). Why negative affectivity should not be controlled in job stress research: Don't throw out the baby with the bath water. Journal of Organizational Behavior, 21, 79-95. http://dx.doi.org/ 10.1002/(SICI)1099-1379(200002)21:1<79::AID-JOB964>3.0.CO;2-G

Stoeva, A. Z., Chiu, R. K., \& Greenhaus, J. H. (2002). Negative affectivity, role stress, and work-family conflict. Journal of Vocational Behavior, 60, 1-16. http://dx.doi.org/10.1006/jvbe.2001.1812

Sumer, H. C., \& Knight, P. A. (2001). How do people with different attachment styles balance work and family? A personality perspective on the work-family linkage. Journal of Applied Psychology, 86, 653- 663. http://dx.doi.org/10.1037/0021-9010.86.4.653

Thoits, P. A. (1987). Gender and marital status differences in control and distress: Common 


\section{Macrothink}

International Journal of Human Resource Studies

ISSN 2162-3058

stress versus unique stress explanations. Journal of Health and Social Behavior, 28, 7-22. http://dx.doi.org/ 10.2307/2137137

Thompson, E.R. (2008). Development and Validation of an International English Big-Five Mini-Markers. Personality and Individual Differences, 45 (6), 542-548. http://dx.doi.org/10.1006/jvbe.2001.1812

Watson, D., Clark, L. A., \& Carey, G. (1988a). Positive and negative affectivity and their relation to anxiety and depressive disorders. Journal of Abnormal Psychology, 97, 346-353. http://dx.doi.org/10.1037/0021-843X.97.3.346

Wayne, J., Musisca, N., \& Fleeson, W. (2004). Considering the role of personality in the work-family experience: Relationships of the big five to work-family conflict and facilitation. Journal of Vocational Behavior, 64, 108-130. http://dx.doi.org/10.1016/S0001-8791(03)00035-6 